\title{
De niño perseguí a los protestantes
}

\section{Discurso en la recepción del diploma y de la medalla de oro de la Liga Española Pro-Derechos Humanos a Juan José Tamayo, por su compromiso y su trabajo intelectual a favor del diálogo entre las religiones'}

Juan José TamaYo

Director de la Cátedra de Teología y Ciencias de las Religiones "Ignacio Ellacuría", Universidad Carlos III de Madrid Secretario general de la Asociación de Teólogos y Teólogas Juan XXIII

Me produce una profunda emoción encontrarme con más de 200 personas reunidas en este lugar tan emblemático de lucha contra la marginación para acompañarme en la entrega del galardón que se me concede. A tantos amigos y amigas aquí reunidos hay que sumar cientos de personas que se han adherido a este homenaje de todas las partes del mundo: profesoras y profesores de 25 universidades de España, Europa, América Latina, India, África y Estados Unidos; instituciones universitarias, asociaciones, fundaciones; personalidades del mundo de la ciencia, de la cultura, del pensamiento, etc. Para todos, muchas gracias por vuestra solidaridad.

Quiero expresar mi agradecimiento a la parroquia de San Carlos Borromeo por facilitar la celebración de este acto tan importante para mí. Aquí tengo mi segunda cátedra en la que doy clase los lunes alternos desde hace 8 años. Agradecimiento que personalizar en Carmen Díaz, Enrique de Castro, Sara Nieto, Pepe Díaz, Patuca Fernández y Javier Baeza, animadores sociales de los que tanto aprendo en materia de derechos sociales, sobre todo de la negación de los mismos entre los sectores más vulnerables de la sociedad.

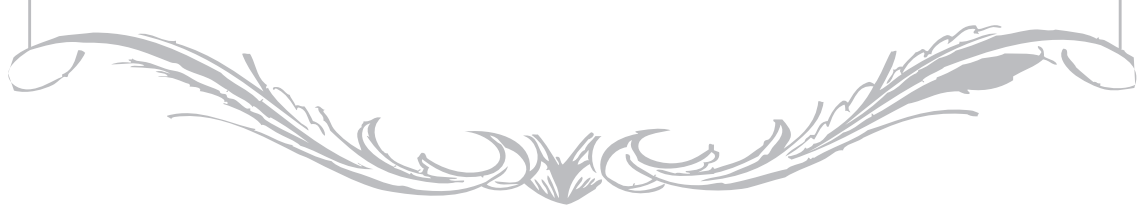


Agradezco, igualmente, la presencia del vicerrector de profesorado Dr. Juan Romo y del decano de la Facultad de Humanidades, Comunicación y Documentación de la Universidad Carlos III de Madrid, quien, en representación del rector, ha tenido palabras de reconocimiento al rigor de mi trabajo académico y a mi capacidad de transmitir los saberes y conocimientos universitarios a la sociedad, dos tareas no siempre fáciles de armonizar. La presencia de numerosos colegas de las diferentes universidades de Madrid en este acto me llena de satisfacción y reflexión la sintonía entre nosotros. A vosotros también mi gratitud.

Doy las gracias muy especialmente a Federico Mayor Zaragoza, director general de la UNESCO durante doce años y presidente de la Fundación Cultura de Paz, por la generosa y literariamente bellísima laudatio que ha hecho de mi persona, dictada sin duda por la amistad y por los muchos años de colaboración conjunta. De él aprendo a diario las lecciones de la paz y del diálogo y admiro su lucidez y capacidad para compaginar dos tipos de lenguaje que parecen difíciles de armonizar: el científico y el poético. Esta vez ha preferido el segundo para que lo entendiéramos todos.

Expreso mi agradecimiento a la Liga Española Pro-Derechos Humanos en la persona de su presidente, Francisco José Alonso Rodríguez, por haberme concedido el Diploma y la Medalla de Oro de la Liga Española Pro-Derechos Humanos en el Primer Centenario de su constitución en noviembre de 1913. ¿Motivo de dicha concesión? Mi trabajo intelectual y mi compromiso cívico en favor del diálogo entre las religiones.

Quiero compartir este premio con cuantas personas y asociaciones colaboro, unas presentes en este acto y otras ausentes, con el objetivo de poner racionalidad en el mundo - con frecuencia irracionalde las religiones; pasar del anatema al diálogo y buscar una respuesta no-violenta por la vía de la justicia y la paz a los conflictos. Es también a ellas, cuya enumeración sería interminable, a quienes corresponde este reconocimiento que hoy se me hace.

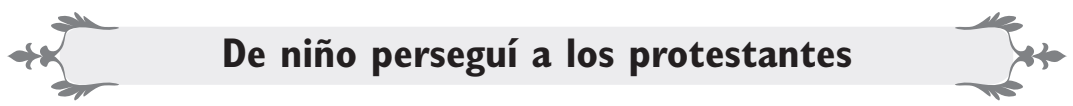

Nada en mis genes anunciaba más cerril fundamentalismo, del que que fuera a trabajar en el estudio de las religiones, y menos aún a trabajar por el diálogo entre las religiones. Todo lo contrario, desde pequeño me inyectaron en vena el tardé en liberarme.

Recuerdo, como si fuere hoy, una escena que lo confirma. Tenía yo ocho años y era un devoto mo- 
naguillo que hacía poco tiempo había tomado la primera comunión. Transcurría pacíficamente un domingo de mayo de 1956 en mi pueblo de la Castilla de Tierra de Campos. Las campanas daban el primer toque que anunciaba la misa de 11. Mi prima, unos años mayor que yo, entró precipitadamente en mi casa y alertó a mi madre de que había dos señores forasteros vestidos de negro que estaban alterando el orden público. "¿Qué hacen?", le preguntó sorprendida mi madre. "Deben ser protestantes, porque están repartiendo Biblias por la casas", respondió mi prima. En aquella época no se podía leer la Biblia sin el permiso del sacerdote. Mi prima le pidió a mi madre que fuera yo a toda prisa a avisar al alcalde de tan grave desorden. $\mathrm{Y}$ eso hice velozmente. Fui a casa del alcalde, que a la sazón era también jefe local del Movimento, y le expliqué lo que estaba pasando. "Efectivamente -dijo el alcalde-, repartir Biblias por las casas es alterar el orden público". "Vete a buscar al alguacil para que los detenga", me pidió. Y eso hice prestamente. Encontré al alguacil en su casa y juntos fuimos a la caza y captura de los hombres de negro. El alguacil los detuvo sin que ellos opusieran resistencia y los encerró en el calabozo, que estaba en el sótano del ayuntamiento. Orgullosos de tal gesta, el alguacil y yo entramos en la iglesia, que está frente al ayuntamiento, y nos decidimos a comulgar, cosa que hicimos sin ningún remordimiento de conciencia. Los dos protestantes pasaron la noche en el calabozo y fueron soltados al día siguiente sin cargos, pero no sin antes advertirlos de que no volvieran a poner un pie en el pueblo. Los cargos nos los tenían que haber puesto a nosotros. Muchas veces he pedido perdón por ese acto de intolerancia que condujo a dos buenas personas a dormir en el calabozo de mi pueblo por el entonces considerado horrendo delito de repartir Biblias por las casas.

\section{Posteriormente, fui condenado por heterodoxo}

Casi sesenta años después, recibo este Premio. ¿Se habrá equivocado la Liga al concederme el Premio? Es posible. Pero todo tiene su explicación. En 2003, fue investigado por la Congregación para la Doctrina de la Fe, mi libro Dios y Jesús. El horizonte religioso de Jesús de Nazaret, publicado por la editorial Trotta tres años antes. El resultado de la investigación fue comunicado a la Comisión para la Doctrina de la Fe de la Conferencia Episcopal Española, quien censuró el libro y me retiró el reconocimiento de "teólogo católico" —a mí, que soy licenciado en teología por la Universidad Pontificia de Comillas y doctor en teología por la Universidad Pontificia de Salamanca (llevo dos tiaras sobre mi cabeza, de las que creo haberle liberado)—, 
como antes lo había hecho Roma con otros colegas como Hans Küng.

¿Delito? Aplicar los métodos histórico-críticos a la lectura e interpretación del Nuevo Testamento y presentar a Jesús de Nazaret como liberador de las diferentes opresiones y de considerar el título de Hijo de Dios como "metáfora de la teología cristiana". Curiosamente, es el libro más religioso que yo he escrito. Lo mismo le pasó a Renan con su Vida de Jesús, libro de honda espiritualidad, amén de rigurosa investigación histórica, que fue condenado y colocado en el Índice de Libros Prohibidos. Justamente un siglo antes, en 1903, Roma condenó el libro del teólogo modernista francés Alfred Loisy, La Iglesia y el Evangelio, por una afirmación, entre otras, que le pareció insultante al Vaticano: "Jesús anunció el Reino y vino la Iglesia". A lo que yo añadí este comentario: "Qué fracaso".

Sucedió que unos años antes me había Ilamado Gregorio Peces Barba como profesor de la Universidad Carlos III, y me hice cargo de la docencia de las materias relacionadas con las ciencias de las religiones.

Ambas situaciones dieron un giro a mi actividad investigadora, a mi docencia y a mis opciones sociorreligiosas y socioculturales.

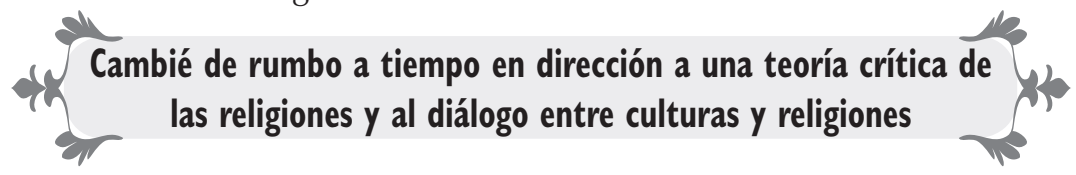

Fue entonces cuando decidí abrir nuevos horizontes en mis investigaciones y en mi actividad pública, y orienté mi trabajo intelectual hacia la elaboración de una teoría crítica de las religiones y de los derechos humanos desde la perspectiva de género y hacia el diálogo de cosmovisiones, espiritualidades, religiones y culturas.

¿Cómo? Participando en el nacimiento y desarrollo de la Asociación para el Diálogo Interreligioso (ADIM); a través de varias publicaciones, entre ellas: Fundamentalismos y diálogo entre religiones (2004; $2^{a}$ ed.: 2009); Islam.
Cultura religión y política (2009; $3^{\text {a }}$ ed.: 2010); Judaísmo, cristianismo e islam: tres religiones en diálogo (2010); Islam: política, sociedad y feminismo (de próxima aparición); con la elaboración de una teoría islamocristiana de la liberación.

No hay razón para el choque de civilizaciones y sí razones para el diálogo entre las religiones. Veamos las sinrazones de choque y las razones del diálogo.

En mis análisis de los conflictos del mundo actual parto de la convicción de que ni el choque de civilizaciones es una ley de la 
historia, ni las guerras de religiones son una constante en la vida de los pueblos, ni los fundamentalismos pertenecen a la naturaleza de las religiones. Son, más bien, construcciones ideológicas del imperio y de las cúpulas religiosas para mantener su poder sobre el mundo y sobre las conciencias de los ciudadanos. Son construcciones ideológicas que manipulan a Dios, a quien se invoca como aliado suyo, y a las religiones, consideradas expresa o tácitamente como sanción moral de sus comportamientos, incluso violentos.

Las religiones no pueden caer en la trampa que les tiende el imperio. No pueden seguir siendo fuentes de conflicto entre sí ni seguir legitimando los choques de intereses espurios de las grandes potencias. La alternativa a la guerra de religiones es el diálogo interreligioso y el trabajo por la paz, que han de convertirse hoy en el imperativo categórico de las distintas tradiciones religiosas y espirituales de la humanidad, si no quieren anquilosarse, ignorarse o, peor todavía, destruirse unas a otras. Y ello por una serie de razones antropológicas, epistemológicas, filosóficas, políticas, interculturales, religiosas y teológicas que expongo a continuación.

1. El diálogo forma parte de la estructura del ser humano. Este, más que lobo para sus semejantes, como pensara Hobbes, es un ser social, y la sociabilidad implica espacios de comunicación, escenarios de encuentro, lugares de diálogo. Por lo mismo, la incomunicación, el desencuentro y el monólogo constituyen la más crasa negación de la sociabilidad y convierten al ser humano en lobo estepario, peor aún, en destructor de sí mismo. La existencia misma del ser humano no se entiende sin referencia al otro, a los otros con quienes comunicarse. Lo expresaba certeramente Desmond Tutu: "Yo soy si tú eres". La madurez y la realización integral de la persona requieren un ámbito de referencia: la projimidad.

El ser moral de la persona implica la alteridad y no se entiende sin la mediación dialógica: la ética comienza cuando los otros entran en escena. La sociabilidad no es un accidente ni una contingencia; es la definición misma de la condición humana, afirma Todorov, quien cita el ensayo de Rousseu Essai sur l' origine des langues: "Aquel que quiso que el hombre fuera sociable tocó con el dedo el eje del globo y lo inclinó sobre el eje del universo". ${ }^{2}$

2. El diálogo forma parte, igualmente, de la estructura del conocimiento y de la racionalidad. La razón es dialógica, no autista; intersubjetiva, no puramente subjetiva. El autismo constituye una de las patologías de la epistemología. Nadie puede afirmar que posee la verdad en exclusiva y en su totalidad. Menos aún decir, remedando al Rey Sol: "La razón soy yo". Todo lo contrario. Es mejor seguir la con- 
signa de Antonio Machado cuando decía: "¿Tu verdad? No, guárdatela. La verdad. Y vamos a buscarla juntos".

El diálogo requiere argumentación, como paso necesario en toda búsqueda y momento vital en el debate; de lo contrario, no se produce avance alguno; siempre se está en el mismo sitio. Argumentación que exige exponer las propias razones, pero también escuchar las razones del otro.

3. El diálogo es una de las claves fundamentales de la hermenéutica. Es la puerta que nos introduce en la comprensión de los acontecimientos y de los textos de otras tradiciones culturales y religiosas o de los acontecimientos y de los textos del pasado de nuestra propia tradición. ¿Qué otra cosa es la hermenéutica sino el diálogo del lector con dichos textos y acontecimientos en busca de significado, de sentido? Gracias a él podemos superar la distancia, a veces abismal, de todo tipo: cronológica, cultural, antropológica, entre los autores y protagonistas de ayer y los lectores de hoy. Sin diálogo con los textos y los acontecimientos, estos no pasan de ser referentes arqueológicos del pasado u objetos de curiosidad sin significación alguna en y para el presente. La conversación, cree David Tracy, puede funcionar como modelo de toda interpretación. A su vez, la religión constituye la realidad más plural, ambigua e impor- tante, al tiempo que la más difícil y, por ello, la mejor prueba para cualquier teoría de la interpretación. ${ }^{3}$

El ser humano vive y actúa, piensa y delibera, comprende $y$ cree, juzga y experimenta, bajo el signo de la interpretación. Coincido con Tracy en que "ser humano es actuar reflexivamente, decidir deliberadamente, comprender inteligentemente, experimentar plenamente. Lo sepamos o no, el ser humano es un hábil intérprete". ${ }^{4}$

Todo acto de interpretación implica tres realidades: un fenómeno a interpretar, alguna persona que lo interprete y la interacción o dialogo entre ambas. El fenómeno a interpretar puede ser una ley, una acción, un símbolo, un texto, un acontecimiento, una persona. La persona que lo interpreta puede ser individual o colectiva. El diálogo entre ambos es precisamente el acto hermenéutico por excelencia.

4. El diálogo se presenta como alternativa al fundamentalismo y al integrismo cultural o religioso, como antídoto frente a la ideología del "choque" o el enfrentamiento entre culturas y religiones y frente a toda amenaza totalitaria. La fuerza del diálogo se impone sobre cualquier otro mecanismo de poder, incluida el militar, al que suele recurrirse para imponer modelos políticos y condiciones absolutas a la convivencia. ${ }^{5}$ 
5. A favor del diálogo interreligioso habla la historia de las religiones, que muestra la riqueza simbólica de la humanidad y la pluralidad de manifestaciones de lo sagrado, de lo divino, del misterio en la historia humana, la diversidad de mensajes y de mensajeros no siempre coincidentes y a veces enfrentados, y las múltiples y diferenciadas respuestas a las múltiples preguntas en torno al origen y el futuro del cosmos y de la humanidad, sobre el sentido de la vida y de la muerte. La uniformidad constituye un empobrecimiento del mundo religioso. Debe reconocerse y afirmarse, por ende, la pluralidad y la diferencia como muestras de la riqueza de dicho mundo. Quizás el frecuente recurso al anatema de los creyentes de unas religiones contra los de otras se deba a la ausencia de la asignatura de historia de las religiones en los curricula escolares y a la presentación de cada religión como único camino de salvación con exclusión de las demás. ${ }^{6}$

6. La verdad no se impone por la fuerza de la autoridad, sino que es fruto del acuerdo entre los interlocutores tras una larga y ardua búsqueda donde se compaginan el consenso y el disenso. Esto es aplicable también al conocimiento teológico. Así se ha operado en los momentos estelares del debate doctrinal dentro de la mayoría de las religiones. La metodología dialógica sustituye a la imposición autoritaria de las propias opiniones por decre- to y quiebra los estereotipos de lo verdadero y lo falso establecidos por el poder dominante, en este caso, por la religión dominante. Es verdad que esta metodología puede desembocar en rupturas, pero estas responden muchas veces a las prisas a la hora de tomar decisiones y a la intransigencia de quienes fijan las reglas de juego. En todo caso, siempre debe evitarse la injerencia de instancias de poder ajenas al ámbito religioso que tienden a manipular las religiones y ponerlas a su servicio.

7. También el enfoque intercultural aboga por el diálogo interreligioso. ${ }^{7}$ Ninguna cultura ni religión pueden considerarse en posesión única de la verdad, como si se tratara de una propiedad privada recibida en herencia o a través de una operación mercantil. Como tampoco una sola religión o cultura tienen la respuesta única a los problemas de la humanidad o la fuerza liberadora exclusiva para luchar contra las opresiones. La verdad, la respuesta a los problemas humanos y la liberación están presentes en todas las religiones y culturas, si bien mezcladas con desviaciones y patologías epistemológicas. ¡Y hay que buscarlas constantemente!

8. El diálogo interreligioso constituye un imperativo ético para la supervivencia de la humanidad, la paz en el mundo y la lucha contra la pobreza. En torno a 5000 millones de seres humanos están 
vinculados a alguna tradición religiosa y espiritual. Y si se ponen en pie de guerra, el mundo se convertiría en un coloso en Ilamas con una capacidad destructiva total. Primero, se unirían todos los creyentes para luchar contra los no creyentes hasta su eliminación. Después, se enfrentarían los creyentes de las distintas religiones entre sí hasta su destrucción, reeditando las viejas guerras religiosas. Muy distinto sería el escenario si las religiones dialogaran y se comprometieran - entre sí y junto con los no creyentes- en el trabajo por la paz, la lucha por la justicia, la defensa de la naturaleza como hogar de los seres humanos, el logro de la igualdad y el reconocimiento de la diversidad. ${ }^{8}$

9. Coincido a este respecto con Raimon Panikkar en que "sin diálogo el ser humano se asfixia y las religiones se anquilosan". Idea que es inseparable de la diversidad, como afirma el filósofo iraní Ramin Jahanbegloo: "Sin diálogo, la diversidad es inalcanzable; $y$, sin respeto por la diversidad, el diálogo es inútil". La interdependencia de los seres humanos, la diversidad cultural, la pluralidad de cosmovisiones, e incluso los conflictos de intereses demandan una cultura del diálogo, como reconocía el Dalai Lama en el discurso pronunciado en el Foro 2000 en Praga: "Siempre habrá en las sociedades humanas diferencias de opiniones y de intereses, pero la realidad hoy es que todos somos interdependientes y tenemos que coexistir en este pequeño plantea. Por lo tanto, la única forma sensata e inteligente de resolver las diferencias y los choques de intereses, ya sea entre individuos o entre países, es mediante el diálogo. La promoción de una cultura del diálogo y de la no violencia para el futuro de la humanidad es una importante tarea de la comunidad internacional".

10. La búsqueda de la (v) Verdad -con mayúscula y con minúscula - es la gran tarea y el gran desafío del diálogo interreligioso. Y ello a sabiendas de que nunca Ilegaremos a poseerla del todo y de que sólo lograremos aproximarnos a ella. El carácter inagotable de la Verdad -con mayúscula- nos disuade de todo intento de apresarla en fórmulas rígidas y estereotipadas. La profundidad de la verdad -con minúscula- nos disuade de creer que hemos llegado al fondo.

El diálogo ha de partir de unas relaciones simétricas entre las religiones y de la renuncia a actitudes arrogantes por parte de la religión que está más arraigada o es mayoritaria en un determinado territorio. Las religiones todas son respuestas humanas a la realidad divina que se manifiesta a través de diferentes rostros. Todas ellas forman un "pluralismo unitario" (P. Knitter), al tiempo que cada una posee una "singularidad complementaria" abierta a las otras. 
Las religiones no pueden recluirse en su propio mundo, en la esfera de la privacidad y del culto, como si los problemas de la humanidad no fueran con ellas. Todo lo contrario, han de activar sus mejores tradiciones para contribuir a la construcción de una sociedad intercultural, interreligiosa, interétnica, justa, fraterna y sororal.

11. A diferencia de las actitudes de enfrentamiento, el diálogo no pretende vencer y derrotar o convencer y obligar a cambiar de opinión al interlocutor, sino buscar elementos de encuentro desde las diferentes posiciones culturales y religiosas. Tampoco busca llegar a síntesis irénicas, pero sí puede crearse un nuevo lenguaje compartido para poder entenderse. No se trata de crear grandes teorías universales, ni una superestructura cultural, sino de favorecer relaciones y entendimientos mutuos donde todos tengan cabida y puedan participar en pie de igualdad. El escenario del diálogo puede proporcionar un proceso de mutuo aprendizaje unos de otros.

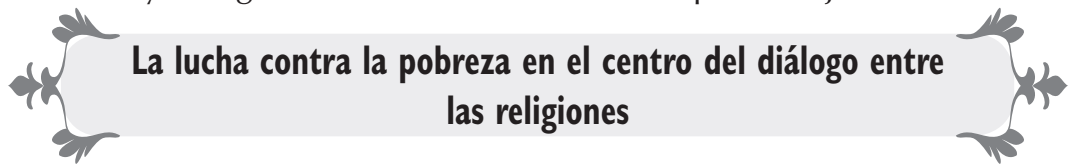

Muchas religiones, muchos pobres, muchos rostros de la pobreza, condicionados todos ellos por la situación económica, agudizados por la economía neoliberal, radicalizados por la dictadura inmisericorde de los mercados. Continentes enteros, regiones, países, sectores sociales sumidos en la pobreza estructural por mor del neoliberalismo: en total, más de dos terceras partes de la humanidad, la mayoría en el Sur, pero también grandes bolsas de pobreza en el Norte rico. Mujeres doble o triplemente oprimidas y discriminadas: por ser mujeres, ser pobres y pertenecer a etnias marginadas. Comunidades indígenas sojuzgadas, comunidades negras sometidas a un régimen de apartheid realmente existente, jóvenes sin trabajo, 6 millones de desempleados, un millón de familias con todos los miembros en paro, incremento de las desigualdades, etc.

Las religiones no pueden pasar de largo ante los diferentes rostros de la pobreza y de los pobres, y en este momento ante las víctimas de la crisis. Han de mostrar sensibilidad hacia ellas y comprometerse en la lucha contra las causas que las provocan. ¿Cómo?:

- Personalmente, viviendo sin ostentación, con austeridad.

- Comunitariamente, a través de la práctica del compartir, experiencia común a las religiones.

- Socialmente, comprometiéndose con los movimientos que luchan por otro mundo posible. 


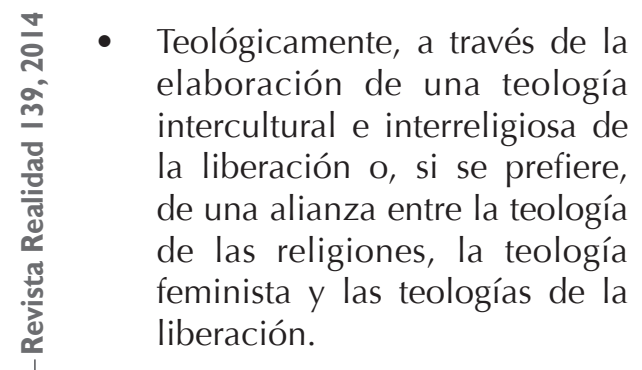

- Ecológicamente, trabajando por un desarrollo sostenible y por una relación no opresora del ser humano hacia la naturaleza.

- Económicamente, construyendo un modelo alternativo al capitalismo neoliberal.

- Desde la perspectiva de género, practicando la democracia paritaria con igual representatividad de hombres en las organizaciones religiosas; reconociendo a las mujeres como sujetos éticos, religiosos, capaces de tomar sus decisiones libremente y en conciencia sin interferencia de las jerarquías religiosas patriarcales; reconociendo y respetando escrupulosamente los derechos sexuales y reproductivos de las mujeres como derechos humanos; incorporando a las mujeres al espacio sagrado, del que han sido separadas por irracionales leyes de pureza e impureza; devolviéndoles el protagonismo que se les ha negado en el ejercicio del poder; reconociéndoles responsabilidades directivas en igualdad de condiciones que los varones; participando en la elaboración de la doctrina moral, hasta ahora impuesta por los varones; haciendo una interpretación de los textos de las religiones desde la perspectiva de género; eliminando el lenguaje patriarcal, en sí mismo discriminatorio y con frecuencia legitimador de la desigualdad y la violencia contra las mujeres.

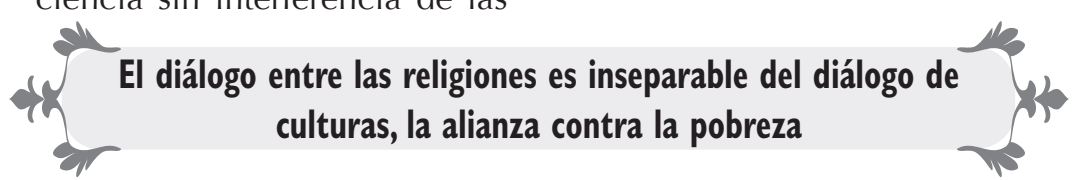

El encuentro de religiones debe ir acompañado del diálogo entre culturas, la alianza de civilizaciones y la lucha contra la pobreza y las desigualdades.

El diálogo de culturas sin diálogo de religiones resulta ineficaz, ya que no pocas culturas tienen su matriz en las religiones. El diálogo entre religiones sin diálogo entre culturas es una operación endogámica. El diálogo entre religiones sin lucha por la justicia es vacío. El encuentro de religiones y el diálogo de culturas sin la alianza contra la pobreza resulta estéril y no pasa de ser una entretenida charla de sobremesa, que puede desembocar en verborrea. 
Pero el diálogo tiene que ser: inclusivo de todas las culturas, civilizaciones, espiritualidades, religiones frente a la tendencia generalizada a excluir tradiciones religiosas, culturales y espirituales minoritarias y ancestrales por considerarlas atrasadas e irrelevantes; contrahegemónico, para ello hay que evitar la distinción entre grandes religiones y religiones minoritarias que convierte a las grandes religiones en hegemónicas y a las minoritarias subalternas, así como cuestionar la legitimación que las grandes religiones hacen de los poderes hegemónicos; transformador de estructuras opresoras y alienantes.

En suma, el niño de los años cincuenta del siglo pasado que
— con tanto celo nacional-católico perseguía a los protestantes-creía que fuera de la Iglesia católica no había salvación. El teólogo y filósofo del diálogo interreligioso de la segunda década del siglo XXI, heterodoxo de todas las ortodoxias -políticas, religiosas, ideológicas y económicas-, está convencido de que sin la convergencia entre el diálogo intercultural, el encuentro de religiones y la alianza contra la pobreza el mundo no tiene salvación.

Con esta convicción camino por la vida mirando al futuro, teniendo como guía a Walt Whittman, quien me ha enseñado la gran lección de seguir adelante contra viento y marea:

\begin{abstract}
Antes del alba subí a las colinas, miré los cielos apretados de luminarias y le dije a mi espíritu: cuando conozcamos todos estos mundos y el placer y la sabiduría de todas las cosas que contienen, ¿estaremos satisfechos? Y mi espíritu dijo: 'No, ganaremos esas alturas para seguir adelante'.
\end{abstract}

Este premio, compartido con vosotros, constituye un aliciente para "seguir adelante". Que no es poco en el mundo de las religiones, donde la mirada suele dirigirse al pasado. Muchas gracias. 
1 Este acto tuvo lugar el 13 de enero de 2014.

2 Tzvetan Todorov, Vida en común, Taurus, Madrid, 2008, p. 33.

3 Cf. David Tracy, Pluralidad y ambigüedad. Hermenéutica, religión, esperanza, Trotta, Madrid, 1997.

$4 \quad$ Ibid., p. 23-24, subrayado mío.

5 Cf. Juan José Tamayo, Fundamentalismos y diálogo entre religiones, Trotta, Madrid, 2009, $2^{a}$ ed.; Juan José Tamayo y María
José Fariñas, Culturas y religiones en diálogo, Síntesis, Madrid, 2007.

6 Cf. Giovanni Filoramo, Marcello Massenzio, Massimo Taveri y Paolo Scarpi, Historia de las religiones, Crítica, Barcelona, 2000; id., Enciclopedia de las religiones, Akal, Madrid, 2001.

7 Cf. Raúl Fornet-Betancourt, Transformación intercultural de la filosofía, Desclée de Brouwer, Bilbao, 2001.

8 Cf. Hans Küng, Proyecto de ética mundial, Trotta, Madrid, 1990. 